\title{
Endodontic management of dens invaginatus of maxillary lateral incisor: A case report Thapaliya R, ${ }^{1}$ iD Joshi $R,{ }^{2}$ iD ${ }^{2}$ Thapa A, ${ }^{3}$ iD Shrestha $R^{4}$ iD
}

${ }^{1}$ Ranjan Thapaliya, Postgraduate Resident; ${ }^{2}$ Reema Joshi, Professor; ${ }^{3}$ Asha Thapa, Associate Professor; ${ }^{4}$ Reetu Shrestha, Associate Professor, Conservative Dentistry and Endodontics Unit, Department of Dental Surgery, National Academy of Medical Sciences, Bir Hospital, Mahabouddha, Kathmandu, Nepal.

\begin{abstract}
Dens invaginatus is a developmental malformation of teeth with the enfolding of enamel and dentin into the pulp chamber and sometimes into the root that most commonly affects the maxillary lateral incisors. This anomaly may increase the risk of pulpal disease and can potentially complicate treatment due to its aberrant anatomy, thus posing a diagnostic challenge. Similarly, the incomplete elimination of the invagination and debridement may create dead space within the canal leading to the failures. This case reports the endodontic management of the Oehler's type II Dens invaginatus.
\end{abstract}

Key words: Cone beam computed tomography; Dens invaginatus; Maxillary lateral incisors; Non-surgical; Sinus opening.

\section{INTRODUCTION}

$\mathrm{D}$ ens invaginatus (DI), also known as dens in dente, is an odontogenic malformation occurring due to deepening or an enfolding of enamel organ into the dental papilla during odontogenesis before calcification. ${ }^{1}$

Its prevalence ranged from $0.3 \%$ to $10 \%$ in Turkish population whereas $0.55 \%$ in North Indian population with more prevalence in male $(0.57 \%)$ than female $(0.53 \%)$ population and most frequently affecting maxillary lateral incisors followed by maxillary canine..$^{1-3}$

\section{Access this article online}

Website: www.jkmc.com.np

DOI: https://doi.org/10.3126/jkmc.v10i1.38974

\section{HOW TO CITE}

Thapaliya R, Joshi R, Thapa A, Shrestha R. Endodontic management of dens invaginatus of maxillary lateral incisor: A case report. J Kathmandu Med Coll. 2021;10(1):55-9.

\footnotetext{
Address for correspondence

Dr. Ranjan Thapaliya Postgraduate Resident

Conservative Dentistry and Endodontics Unit, Department of Dental Surgery,

National Academy of Medical Sciences,

Bir Hospital, Mahabouddha, Kathmandu, Nepal.

E-mail address: thapaliyaji@gmail.com
}

Copyright $\odot 2021$ Journal of Kathmandu Medical College (JKMC)

ISSN: 2019-1785 (Print), 2091-1793 (Online)
Radiograph shows a radio-opaque invagination similar in density to enamel, extending into the central region of the crown at a variable distance from the tooth. Oehler has classified it, according to the extent of the invagination inside the tooth, into three categories (Table 1). ${ }^{4}$

It poses challenges during diagnosis and endodontic management.

\section{CASE REPORT}

A 30-year-old female patient was referred to the Conservative Dentistry and Endodontics Unit, Department of Dental Surgery, Bir hospital with a history of repeated swelling and pus discharge from the upper front teeth region for four months. Medical history was found non-contributory. Previous treatment history revealed that the root canal treatment was started but failed to heal the sinus. Similarly, extraoral examination revealed no significant findings.

Intraoral clinical examination revealed the sinus in the periapical region of tooth \#9 (according to the universal teeth numbering system) with mild inflammation (Figure 1). The tooth was clinically sound and responded to sensibility testing but tooth \#10 had the temporary restoration suggesting the commencement of endodontic procedure (Figure 2). Intraoral periapical (IOPA) radiograph revealed a well-circumscribed radiolucent area $(2 \times 2 \mathrm{~mm})$ at the apex of tooth \#10, 
suggestive of a periapical pathological lesion (Figure 3). The radiographic examination of sinus tracing with gutta percha cone showed the tooth \#10 to be the offending tooth (Figure $4 \mathrm{~A}, \mathrm{~B}$ ).

The IOPA radiograph of tooth \#10 showed an unusual root canal with an identical tooth-like structure within the canal. Hence, a cone beam computed tomography (CBCT) scan was taken (Sirona Orthophos SL-3D) (Figure 5). Coronal slices showed the presence of three separate canals: mesial, central and distal (Figure 5). The axial and cross-sectional views showed the mesial and distal canals converging short of the apex and the central canal not communicating with the other two. Based on these peculiar clinical and radiological features, a definitive diagnosis of dens in dente (Oehler's Type II) was established. ${ }^{4}$

Then, the continuation of the root canal treatment commenced with rubber dam isolation. The access cavity was refined with Endo-Z bur (Maillefer, Dentsply) (Figure 6 A, B) and the central canal was negotiated. The enamel-like white and hard tooth structure was noted circumscribing the canal (Figure 6C). The wall of the access cavity was extended mesially and distally that exposed the mesial, central and distal canal respectively (Figure 6C). The canal orifices were refined and negotiated with No 10 SS file (DiaDent). The canals were irrigated

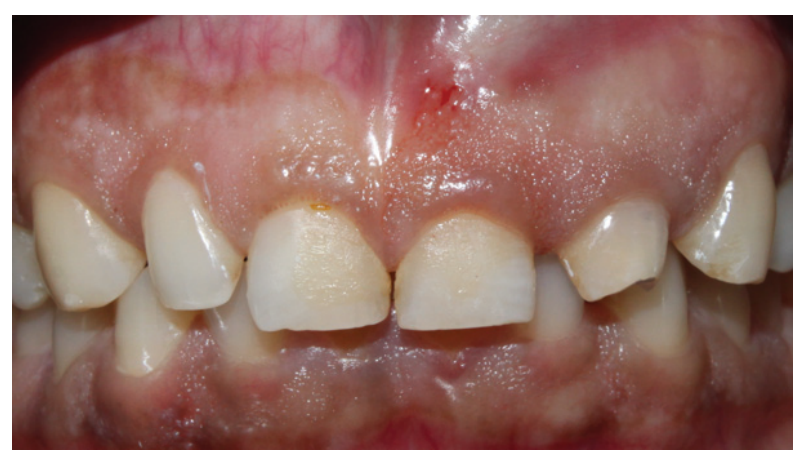

Figure 1: Preoperative radiograph labial view

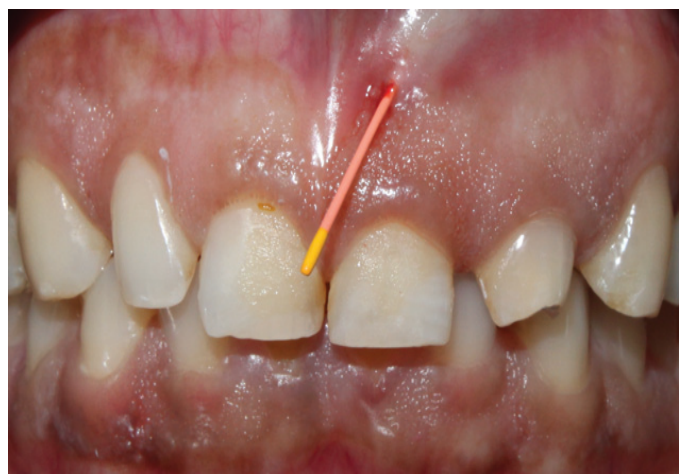

Figure 4A: Sinus tracing with GP cones Sinus tracing with GP cones with $3 \%$ sodium hypochlorite $(\mathrm{NaOCl})$ and normal saline. Then, an electronic apex locator (Eighteeth) was used to determine the working length of the canals (mesial and distal $19.5 \mathrm{~mm}$ and central $18.5 \mathrm{~mm}$ ) and confirmed radiographically (Figure $8 \mathrm{~A}$ ). The canals were enlarged to No 20 SS file and calcium hydroxide intracanal dressing was placed.

The sinus opening was healed in the second appointment scheduled after seven days (Figure 7). Then, cleaning and shaping the canal was done with Hyflex CM files sequentially with 0.04 taper No 20 as master apical file. The pre-obturation cone fit radiograph was taken (Figure 8B). After copious irrigation with $3 \% \mathrm{NaOCl}$ along with manual dynamic agitation, $17 \%$ ethylenediaminetetraacetic acid (EDTA) and final irrigation with $2 \%$ chlorhexidine, the canals were dried with absorbent paper points. The resin-based sealer (Dia-Proseal, DiaDent) was applied to the canal walls and obturation was done with lateral compaction technique. Then, the final restoration of the access chamber was done with glass ionomer cement and the post treatment radiograph was taken to evaluate the degree and quality of obturation (Figure 8C). After two months, the tooth was clinically sound and the follow up radiograph (Figure 8D) showed reduction in the size of the periapical radiolucency suggesting healing.

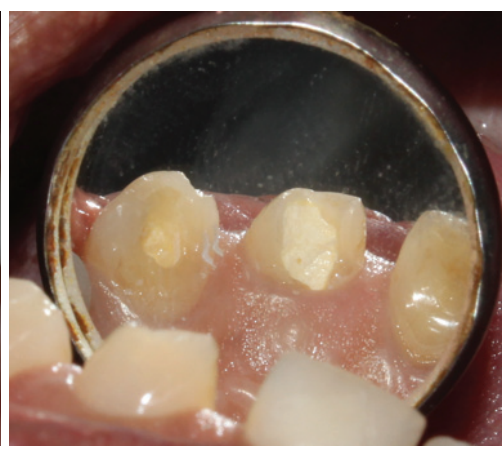

Figure 2: Preoperative radiograph palatal view

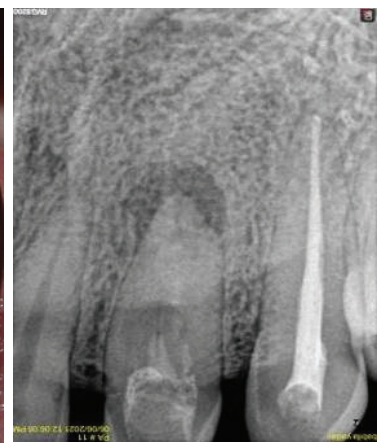

Figure 3: IOPA showing periapical radiolucency

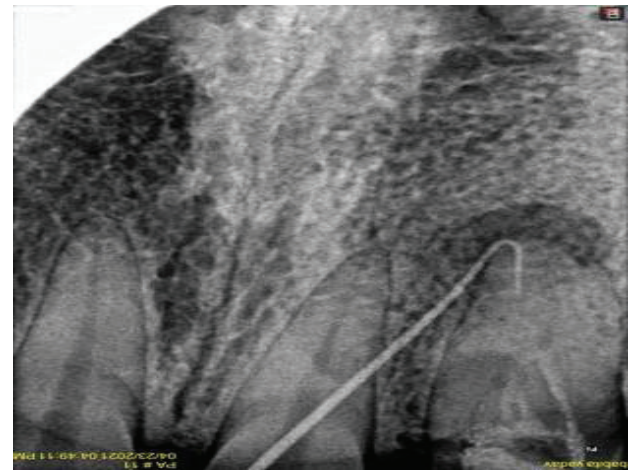

Figure 4B: IOPA with GP sinus tracing 


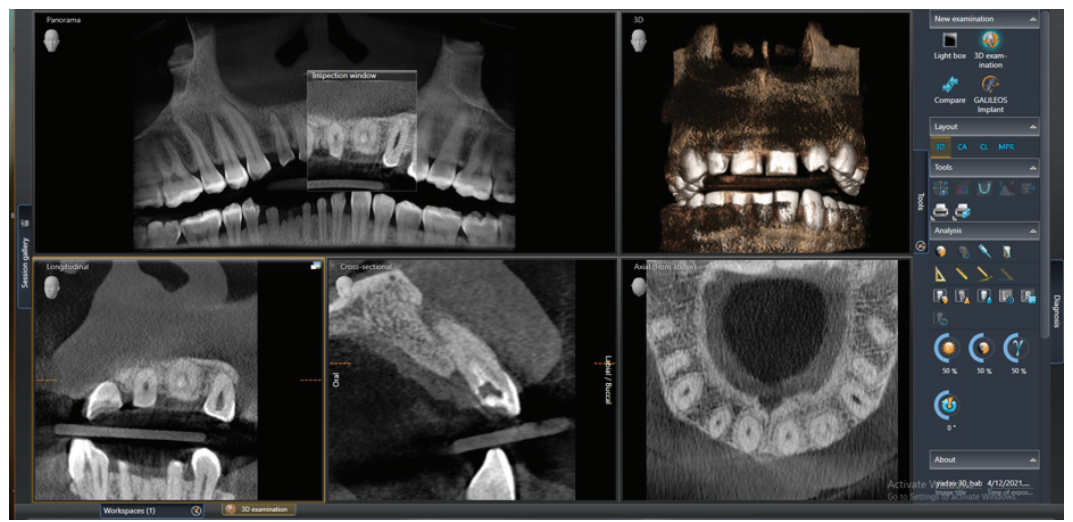

Figure 5: CBCT showing axial, cross-sectional view images

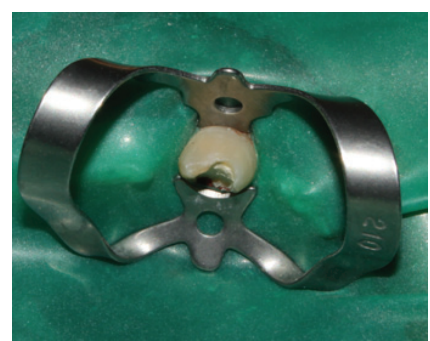

Figure 6A, 6B, 6C: Intraoperative photographs
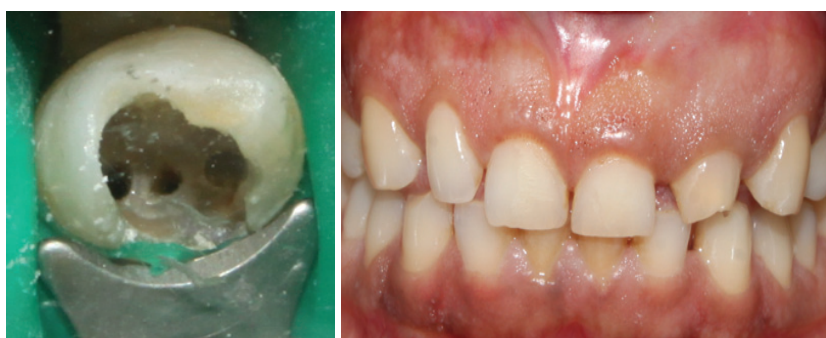

Figure 7: Healed sinus opening
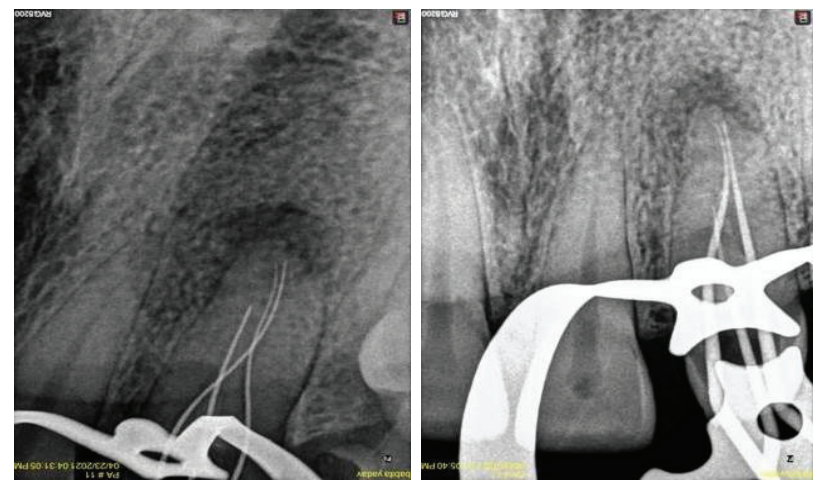

Figure 8A: Working length Figure 8B: Pre-obturation confirmed radiographically cone-fit radiograph
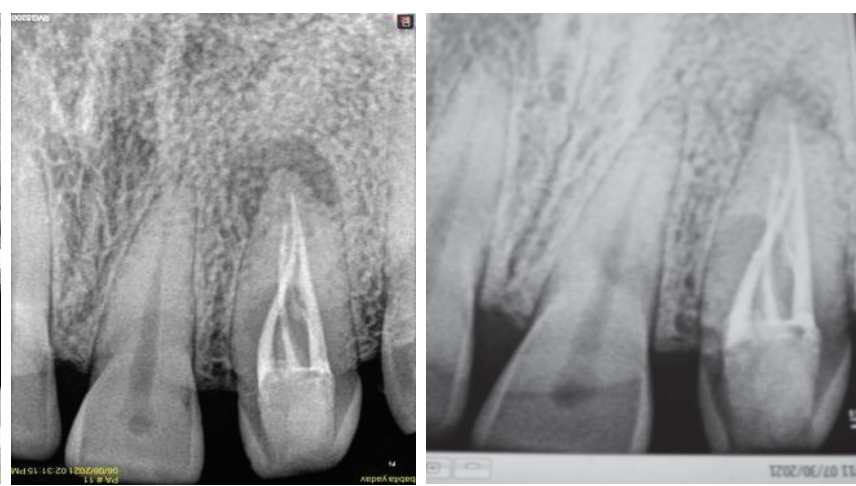

Figure 8D: Two months follow up IOPA

\section{Table 1: Oehler's classification according to the extent of the invagination inside the tooth}

Type 1 This is an enamel-lined invagination that is minimal, confined within the crown, and does not extend beyond the cementoenamel junction.

Type 2 The enamel-lined invagination invades into the root but remains within a blind sac. However, there may be communication with the pulp.

There is usually no communication with the pulp, which lies compressed within the wall around the invagination process. The invagination may appear to be completely lined by enamel, but more often a portion of it is lined

Type 3A by cementum instead. The invagination communicates with the periodontal ligament with a "laterally located" foramen.

Type 3B

The anatomy of the invagination and pulp are similar to type $3 \mathrm{~A}$. The invagination communicates with the periodontal ligament with an "apically located" foramen. 


\section{DISCUSSION}

Dens invaginatus is the dental anomaly with controversial and unclear aetiology. Kronfeld speculated that dens invaginatus is caused by a failure in growth of the internal dental epithelium while at the same time there is also a proliferation of the surrounding normal epithelium, producing a static area of engulfing whereas Oehler proposed that distortion of the enamel organ during tooth development and subsequent protrusion of a part of the enamel organ will lead to the formation of an enamel-lined channel ending at the cingulum or occasionally at the incisal tip. ${ }^{4}$

Dens invaginatus requires early diagnosis and intervention because they are more susceptible to caries due to the presence of deep pits and structural defects. These defects have malformed enamel and fine canals leading to communication with the pulp. The tooth may show no clinical features of any abnormal structure and be detected incidentally on a radiograph taken for another indication.

Teixido et al. (2014) highlighted the use of CBCT as an auxiliary tool for diagnosis and treatment planning of teeth with such developmental anomalies. ${ }^{5}$ In the present case, IOPA failed to show the complex feature. So, the $C B C T$ images helped to recognise the presence of multiple separate canals within the root canal system.

Dens invaginatus is associated with changes in the morphology of the root canal system. De Smit and Demaut found the root canal to be irregular in cross section, with wavelike constrictions and dilatations. ${ }^{6}$ There are reports of multiple root canals being present in association with DI.?

\section{REFERENCES}

1. Hülsmann M. Dens invaginatus: aetiology, classification, prevalence, diagnosis, and treatment considerations. Int Endod J. 1997;30(2):79-90. [PubMed | Full Text | DOI]

2. Gündüz K, Çelenk $P$, Canger EM, Zengin $Z$, Sümer $P$. A retrospective study of the prevalence and characteristics of dens invaginatus in a sample of the Turkish population. Med Oral Patol Oral Cir Bucal. 2013;18(1):e27-32. [PubMed | Full Text | DOI]

3. Patil S, Doni B. Prevalence of dens invaginatus in north Indian population. Oral Maxillofac Pathol J. 2013;4(1):282-8. [Full Text]
Non-surgical endodontic treatment in teeth with dens invaginatus should be the first treatment alternative. However, endodontic treatment of dens invaginatus type II and III can become complicated because of an unpredictable internal anatomy. Endodontic instruments alone are not sufficient to clean and shape irregular spaces such as isthmuses. Thus, they require the instruments that can adapt to the internal anatomy. ${ }^{8}$ Furthermore, DI can be treated using ultrasonic devices under magnification. However, this technique might remove excessive tooth structure and compromise the structural integrity and long-term prognosis. ${ }^{9}$ A study by Neelakantan et al. (2016), showed Manual Dynamic Agitation (MDA) to be equally effective to endovac, passive ultrasonic activation (PUI) and syringe irrigation with superior cleaning efficacy of MDA over $\mathrm{PUI}$ in apical 1 and $3 \mathrm{~mm} .{ }^{10}$ Hence, despite the different methods available, this case has been managed with minimum instrumentation but relying on the increased concentration of $\mathrm{NaOCl}(3 \%)$ as irrigant with manual dynamic agitation and calcium hydroxide as an intracanal medication between appointment.

In multiple reported cases, the conventional endodontic therapy was successful and sufficient enough to eliminate the infectious process of the root canal system, allowing periapical bone formation and absence of symptoms. ${ }^{6,9}$ Similarly, in the present case, the clinical signs of healing was evident after cleaning and shaping of the root canals as the resolution of the sinus opening and radiographic signs of healing at two-month follow-up as the reduction in the size of periapical radiolucency. Furthermore, long term follow-up is required to assess the success of the treatment.

\section{Conflict of interest: None Source(s) of support: None}

4. Oehlers FAC. Dens invaginatus (dilated composite odontome): I. Variations of the invagination process and associated anterior crown forms. Oral Surg Oral Med Oral Pathol. 1957;10(11):1204-18. [PubMed | Full Text | DOI]

5. Teixidó M, Abella F, Duran-Sindreu F, Moscoso S, Roig $M$. The use of cone-beam computed tomography in the preservation of pulp vitality in a maxillary canine with type 3 dens invaginatus and an associated periradicular lesion. J Endod. 2014;40(9):1501-4. [PubMed | Full Text | DOI]

6. De Smit A, Demaut L. Nonsurgical endodontic treatment of invaginated teeth. J Endod. 
1982;8(11):506-11. [PubMed | Full Text | DOI]

7. Kottoor J, Murugesan R, Albuquerque D. A maxillary lateral incisor with four root canals. Int Endod J. 2012;45(4):393-7. [PubMed | Full Text | DOI]

8. Metzger Z, Teperovich E, Zary R, Cohen R, Hof R. The self-adjusting file (SAF). Part 1: respecting the root canal anatomy - A new concept of endodontic files and its implementation. J Endod. 2010;36(4):679-90. [PubMed | Full Text | DOI]
9. Narayana P, Hartwell GR, Wallace $R$, Nair UP. Endodontic clinical management of a dens invaginatus case by using a unique treatment approach: A case report. J Endod. 2012;38(8):11458. [PubMed | Full Text | DOI]

10. Neelakantan P, Devraj S, Jagannathan N. Histologic assessment of debridement of the root canal Isthmus of mandibular molars by irrigant activation techniques Ex Vivo.2016 Aug;42(8):1268-72. [PubMed | Full Text | DOI] 